\title{
Myopathy with hexagonally cross-linked tubular arrays
}

INSERM

\section{Source}

INSERM. (1999). Orphanet: an online rare disease and orphan drug data base. Myopathy with hexagonally cross-linked tubular arrays. ORPHA:171889

Myopathy with hexagonally cross-linked tubular arrays is a rare, congenital, nondystrophic, mild, slowly progressive, proximal myopathy characterized by exercise intolerance and post-exercise myalgia without rhabdomyolysis, associated with highly organized hexagonally cross-linked tubular arrays in skeletal muscle biopsy. Additional features may include muscle atrophy (or diffuse hypotrophy), myalgia with or without musclar weakness, paresis of truncal and limb-girdle musculature, minimal ptosis, lumbar hyperlordosis, decreased deep tendon reflexes, contractures and pes equinovarus. 